\title{
World Bank fund finds allies and sceptics
}

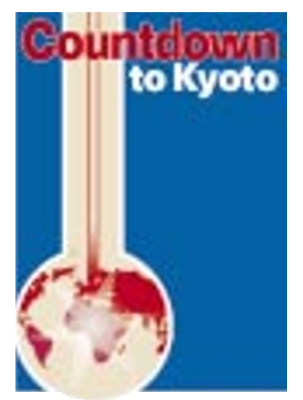

[LONDON] The World Bank has offered to set up and manage a fund to help combat global warming. Under the scheme, known as the Global Carbon Initiative, developed countries would pay for lowcost energy-efficient projects in developing countries. The ensuing greenhouse gas savings could then be credited to the donors' legally binding target of greenhouse gas emissions under a system known as 'joint implementation'.

The bank aims to collect US $\$ 100$ million, and has begun to gather support for the idea. Switzerland, Norway, Finland, Sweden, the Netherlands and several private corporations have already expressed an interest in getting involved. The fund would invest in carbon-abatement projects in the bank's client countries. The bank says it has access to US\$6-billion-worth of projects, encompassing energy, industry, transport and land use.

The bank would act as investment manager and decide on the portfolio of projects. Apart from obtaining carbon or other greenhouse credits, the advantage for investors, it says, is that projects would be considerably cheaper than comparable ventures in developed countries. Developing countries would benefit from the creation of jobs, technology transfer and the spread of energy-efficient technology.

But developing countries and some nongovernmental groups have yet to be convinced of the scheme's merits. Critics fall into two camps: those who disagree with both the concept and the World Bank's involvement, arguing that the idea represents the interests of Western investors and governments; and those who agree with the idea of joint implementation, but are uncomfortable about the bank's potential role as monopoly provider.

Anil Agarwal, director of the Centre for Science and Environment in New Delhi, is in the first category. He was asked by the Indian government to comment on the proposals, and plans to recommend their rejection, partly because the scheme assumes two standards of living: a lower one for developing countries and a higher standard for the developed world.

In an editorial in the latest issue of the centre's fortnightly magazine Down To Earth, Agarwal writes that the bank wants to "buy the rights of present and future generations of Indians to the common atmosphere. And would sell their rights so cheap that even the American Indians who sold New York for a few beads, or the Russians who sold Alaska for a few dollars, would be rich in comparison."

Some others who are broadly in favour of joint implementation are also nervous. Kilaparti Ramakrishna, director of the science and public affairs programme at the Woods Hole Research Center in Massachusetts, says that for many countries the concept is not at issue. "The problem is with the World Bank, which has a major credibility problem in many countries."

Ramakrishna says some members of the Group of 77 developing countries are unhappy about the bank being given the authority to decide in which countries to invest. He says they would prefer the flexibility of dealing directly with donor countries and private corporations.

Ramakrishna adds that developing countries are also concerned that the new fund could interfere with the planned replenishment by governments of the Global Environment Facility (GEF), a United Nations environmental fund that is administered through the World Bank.

But Johannes Heister, a World Bank economist in Washington DC who helped to design the initiative, says such concerns are misplaced. He points out that the fund would not begin until next year, well after

the GEF's replenishment.

He says that donor countries have promised that their investments would not affect how much they will give to the GEF. The amount pledged, he adds, is minimal compared to the expected $\$ 2-\$ 3$ billion GEF replenishment.

Heister argues that the bank will simply be providing a service that will be needed if joint implementation is agreed on in December at the annual conference of the international climate convention in Kyoto, Japan. He says the bank is uniquely placed to obtain sufficient finance, which is essential to the success of joint implementation. "It is an open market. Anyone can get involved."

He adds that the bank has long experience of dealing with governments and the clout to obtain private-sector finance. Transaction costs for World Bank projects are also significantly lower than those incurred through bilateral deals.

But the bank recognizes that its plan would work only if the Kyoto conference results in agreement on legally binding greenhouse gas emissions targets - and if such a treaty includes the principle that countries can receive greenhouse credits by paying for emissions reductions in other parts of the world.

EhsanMasood

\section{Kyoto 'dress rehearsal' ends in deadlock}

[LONDON] Two weeks of negotiations towards a treaty on greenhouse gas emissions ended in Bonn last week as they had begun - in deadlock. One observer described the meeting as "little more than a dress rehearsal" for the climate convention's annual conference next month in Kyoto, Japan.

The Bonn meeting's chairman, Raúl EstradaOyuela of Argentina, remarked that negotiations seemed locked in a 'time warp' with delegations repeating positions he had heard three decades ago. Demands from the European Union and developing countries for a 15 per cent reduction in emissions below 1990 levels by 2010 continue to be opposed by the United States, which favours stablilizing emissions at 1990 levels.

The United States continues to insist that commitments by developing countries must be part of the Kyoto protocol. Australia refuses to sign any legally binding protocol, despite earlier signs that it might do so (see Nature 389, 893; 1997). Japan's compromise proposal of a 5 per cent reduction between 2008 and 2012 now seems the only realistic option on the table.

Estrada successfully resisted US attempts to include developing country commitments in the formal text of the protocol. These will now be discussed separately at Kyoto. But the United States angered many delegates by suggesting on the last day of the meeting that armed forces should be exempt from an emissions reduction protocol.

The draft document that now goes to Kyoto contains 10 articles, two annexes and an attachment, most of

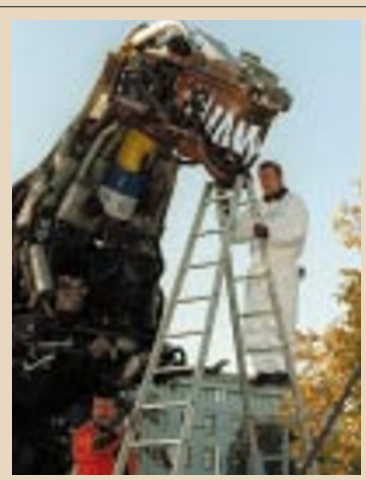

Spot the dinosaur: Greenpeace protests at Bonn meeting.

which are full of blocks of square brackets - denoting text that has yet to be agreed. The most heavily bracketed part relates to the timing and size of greenhouse gas reductions, whether reductions should be calculated according to a 'basket' of gases or individual gases, and whether reductions should be calculated annually or as an average over a period of years.

E.M. 